\title{
An Integrated Methodology for Supplier Selection under the Presence of Vagueness: A Case in Banking Sector, Turkey
}

\author{
Semih Onut ${ }^{1}$ and Suleyman Tosun ${ }^{2}$ \\ ${ }^{1}$ Department of Industrial Engineering, Mechanical Faculty, Yildiz Technical University, Yildiz, 34349 Istanbul, Turkey \\ ${ }^{2}$ Aktif Investment Bank, Büyükdere Caddesi No. 163, Zincirlikuyu, 34394 Istanbul, Turkey \\ Correspondence should be addressed to Semih Onut; onut@yildiz.edu.tr
}

Received 22 January 2014; Accepted 25 April 2014; Published 15 May 2014

Academic Editor: Ray K. L. Su

Copyright (c) 2014 S. Onut and S. Tosun. This is an open access article distributed under the Creative Commons Attribution License, which permits unrestricted use, distribution, and reproduction in any medium, provided the original work is properly cited.

\begin{abstract}
A supplier selection process mainly involves evaluation of different alternative suppliers based on different criteria. This process can be handled as a combination of the customer needs and the technical requirements. Also customers can be considered as the companies to purchase the suppliers' technical expertise. Hence, this kind of relationship can be analyzed as a house of quality model typical of quality function deployment (QFD). This paper develops a supplier evaluation approach based on the analytic network process (ANP), QFD, and the technique for order performance by similarity to ideal solution (TOPSIS) methods to help an investment bank in Turkey as a real world application. Fuzzy logic is used to capture the vagueness in people's verbal assessments. In the first phase, matrices used to define the importance of the supplier selection criteria and the technical requirements are calculated with the fuzzy ANP method. The technical requirements and the criteria are combined in the house of quality to evaluate the relationship between them. In the second phase, fuzzy TOPSIS is used to rank the suppliers based on the weighted criteria obtained from the first phase. The study was followed by the sensitivity analysis of the results.
\end{abstract}

\section{Introduction}

Supplier selection is one of the most widely researched areas in purchasing with methodologies ranging from conceptual to empirical and modeling streams [1]. The selecting process mainly involves evaluation of different alternative suppliers based on different criteria. This process is essentially affected by different tangible and intangible criteria including price, quality, performance, technical capability, and delivery. A number of alternative approaches have been proposed to take these criteria into account, namely, mathematical programming models, multiple attribute decision aid methods, cost-based methods, statistical and probabilistic methods, combined methodologies, and other methods.

This paper is aimed at calculating the weights of criteria and technical requirements used to evaluate suppliers in the procurement process of a project and use them to select the appropriate supplier with the proposed methodology. Quality function deployment (QFD) is employed for combining the supplier selection criteria and required technical needs. It uses a matrix called house of quality. Due to the high degree of subjectivity in constructing the house of quality, the application of fuzzy logic provides an efficient tool to handle the subjective assessments. The methodology consists of eleven steps. In the first four steps, the criteria are defined and related matrices are calculated with the fuzzy analytical network process (fuzzy ANP) method and by the comments of the procurement experts. Then, the criteria are used to define the technical requirements by the technical experts. Fuzzy ANP is used to evaluate the inner dependence of them. The technical requirements and the criteria are combined in the house of quality to evaluate the relationship between them. In the last two steps, fuzzy technique for order performance by similarity to ideal solution (fuzzy TOPSIS) is utilized to select the best supplier as an alternative, based on the weighted criteria achieved from the previous steps.

Supplier selection is viewed as a combination of customer requirements and engineering requirements. Customers are the companies that purchase the technical expertise of the suppliers. Therefore, such a company-supplier relation can be 
viewed as a "house of quality" typical of a QFD model. QFD is one of the techniques that is aimed at the satisfaction of the customer preferences. It enables the companies to become proactive to quality problems rather than taking a reactive position by acting on customer complaints. A QFD planning matrix is used to translate the requirements into measurable supplier evaluation criteria [2,3]. The QFD process involves various inputs that are assessed by decision makers. The assessed values are usually subjective or imprecise. In traditional QFD, they are assumed to be precise and assigned as crisp values. However, it may be more appropriate to treat them as being fuzzy rather than precise. To appropriately quantify these subjective, imprecise, or uncertain assessed values, a number of researchers have applied the fuzzy set theory to QFD and have developed various fuzzy QFD methods [4].

Despite its wide implementation in various areas in the literature, accurate determination of customers' needs or the weights of the supplier evaluation criteria in this study and the technical requirements continue to be a critical issue in QFD design services. This is mainly a result of the failure in prioritizing customer requirements and determining accurate importance levels of service requirements. In order to avoid these problems, the ANP, as a multiple-criteria decision-making (MCDM) method, is utilized to incorporate the inner dependence issues into customer needs and technical requirements in the house of quality. Among the available multiattribute decision-making methods, only the ANP can be used to evaluate the customer needs and technical requirements systematically due to the dependencies and feedbacks caused by the mutual effects of the criteria. There are many weight calculation procedures, but the ANP has some advantages. One of the most important advantages of the ANP is based on pairwise comparison. Furthermore it considers the dependencies and feedbacks of the criteria.

It is very difficult to develop a selection criterion that can precisely describe the preference of one supplier over another. Most of the selection parameters cannot be given precisely and the evaluation data of the alternative suppliers' suitability for various subjective criteria and the weights of the criteria are usually expressed in linguistic terms by the decision makers. This makes fuzzy logic a more natural approach to this kind of problems. The ANP method deals only with crisp comparison ratios. However, uncertain human judgments with internal inconsistency obstructing the direct application of the ANP are frequently found. To cope with this problem, the fuzzy ANP method can be used [5]. In the fuzzy ANP, linguistic assessments are converted to triangular fuzzy numbers. These triangular fuzzy numbers are used to build a pairwise comparison matrix for the ANP. In the fuzzy ANP, weights are simpler to calculate than in the conventional ANP. These weights can be integrated to determine the best alternative to be selected [6]. Contrary to conventional fuzzy ANP methodology in the literature, the linguistic assessment is first converted to (triangular) fuzzy numbers in our proposed methodology. These triangular fuzzy numbers are then used to build pairwise comparison matrices for the ANP. In the fuzzy ANP, weights are more simple to calculate than in the conventional ANP.
There are a number of studies related to the integration of the ANP and QFD under the presence of vagueness. Some examples are given as follows. Büyüközkan et al. [7] developed a combined fuzzy ANP and QFD methodology to prioritize technical design requirements by taking into account the degree of the interdependence between the customer requirements and technical design requirements and the inner dependence among them. In another study presented by the same authors, the basic product planning stage of a car design process was analyzed by using the combined ANP-QFD methodology under a fuzzy environment [8]. Kahraman et al. [9] proposed an integrated framework based on fuzzy-QFD and a fuzzy optimization model to determine the technical product requirements to be considered in designing a product. The coefficients of the objective function were obtained from a fuzzy ANP approach. In another study Liu and Wang [4] described a QFD model based on the fuzzy ANP approach to systematically take into account the interrelationship between and within the QFD components. The proposed method was aimed at expanding the current research scope from the product planning phase to the part deployment phase to provide product developers with more valuable information. Similarly a framework with two phases was constructed for facilitating the selection of engineering characteristics for product design by Lee et al. [10]. In the first phase, QFD was incorporated with the supermatrix approach of the ANP and the fuzzy set theory to calculate the priorities of engineering characteristics with the consideration of the interrelationship among factors and the impreciseness and vagueness in human judgments and information. In the second phase, a multichoice goal programming model was constructed by considering the outcome from the first phase and other additional goals. Geng et al. [11] focused on how to achieve the importance measures of product and service specifications to sufficiently satisfy the customer requirements. QFD was used to translate customer requirements identified in the customer domain to engineering characteristics in the functional domain. The initial importance weights of engineering characteristics were determined using the supermatrix approach of the ANP based on the QFD-ANP model under fuzzy environment. Lin et al. [12] developed a fuzzy ANP and QFD model with interdependence relations of environmental production requirements and sustainable production indicators for an original equipment manufacturing firm in Taiwan. Güngör et al. [13] proposed the use of the fuzzy decision-making system and fuzzy ANP to incorporate the inner dependence issues into customer needs and design requirements in house of quality. Similarly Li et al. [14] also proposed the use of the ANP to incorporate the inner dependence into customer needs and properties in house of quality. In another study, Ertay et al. [15] presented a fuzzy ANP based methodology to rank engineering characteristics for implementing QFD in a fuzzy environment. Lee and Lin [16] developed a systematic framework that incorporates fuzzy Delphi method, fuzzy interpretive structural modeling, and fuzzy ANP into QFD for new product development. In another method proposed by Liu [17], two-stage QFD charts were used to identify customer requirements, engineering characteristics, and evaluation attributes. A fuzzy ANP method was described to derive QFD component weights in terms of fuzzy numbers in this study. 
In this study fuzzy TOPSIS is used to determine the most proper supplier alternative using the supplier weights attained by the fuzzy ANP and QFD methodologies. We use triangular fuzzy numbers in all pairwise comparison matrices in this methodology. Hence, supplier weights are calculated as triangular fuzzy numbers and then these fuzzy supplier weights are inserted to the fuzzy TOPSIS methodology to rank the supplier alternatives. TOPSIS is a widely accepted multiattribute decision-making technique due to its sound logic, simultaneous consideration of the ideal and the antiideal solutions, and easily programmable computation procedure [18]. This technique is based on the concept that the ideal alternative has the best level for all attributes, whereas the negative ideal is the one with all the worst attribute values. In fuzzy TOPSIS, attribute values are represented by fuzzy numbers. Using this method, the decision maker's fuzzy assignments with different rating viewpoints and the tradeoffs among different criteria are considered in the aggregation procedure to ensure more accurate decision making $[19,20]$.

Supplier evaluation and selection have received considerable attention in the literature. Since we used the ANP, QFD, and TOPSIS methods under fuzzy environment, we only focused on the supplier selection literature related to these methods and similar approaches. Some examples of the supplier selection literature related to the fuzzy ANP, fuzzy QFD, and fuzzy TOPSIS are given as follows. Onesime et al. [3] employed the AHP first to measure the relative importance weighting for each of the requirements in the QFD process. Secondly, it was used to assess the evaluating score for each of the candidate suppliers for each particular supplier-evaluating criterion. In another study presented by Bevilacqua et al. [21], a fuzzy QFD approach was suggested to the supplier selection process for a medium-to-large industry that manufactures complete clutch couplings. Amin and Razmi [22] proposed a framework on the basis of a company's strategy for supplier management including supplier selection, evaluation, and development under a fuzzy environment. In the first phase, QFD was utilized to rank the best suppliers based on qualitative criteria. Then, a quantitative model was adopted to consider quantitative metrics. Similarly a methodology combining fuzzy set theory and QFD to establish a housing refurbishment contractor selection model was developed by Juan et al. [23]. Bhattacharya et al. [2] described a concurrent engineering approach integrating the analytic hierarchy process with QFD in combination with cost factor measure to rank and select candidate suppliers under multiple criteria. Onut et al. [24] presented a supplier evaluation approach based on the ANP and TOPSIS methods to help a telecommunication company in the GSM sector in Turkey under the fuzzy environment. Büyüközkan and Çifçi [25] suggested a novel hybrid MCDM approach, where DEMATEL, ANP, and TOPSIS in fuzzy environment were used in order to evaluate green suppliers for the need of improving green supply chain management initiatives. In the same year, a hybrid model composed of fuzzy logic, AHP, and QFD was proposed by Soroor et al. [26] to evaluate and select the best supplier. Dai and Blackhurst [27] designed an integrated analytical approach, combining AHP with QFD to enable the "voice" of company stakeholders in the process.
In another study, Wu et al. [28] developed a hybrid MCDM model including the fuzzy Delphi method, ANP, and TOPSIS, adjusted to the experts' professional consensus to select the optimal supplier.

Although different methods and combinations of them have been applied to many supplier selection problems, the combinations of the ANP, QFD, and TOPSIS have received much less attention in the literature. Furthermore the combinations of the ANP, QFD, and TOPSIS have also received much less attention in the supplier selection literature. Although there were a lot of publications selecting the most suitable supplier alternatives in the literature and some of them have been prepared using the multiattribute/multicriteria decision-making methods considering human judgments and tangible, intangible, and multiple criteria, there is no evidence in the literature that any of them were prepared with the aim of the selection of the suitable supplier using integrated ANP, QFD, and TOPSIS methodology under a fuzzy environment. Our study proposes an integrated fuzzy ANP, QFD, and TOPSIS methodology for evaluating and selecting the most suitable suppliers for an investment bank in Turkey as a real world application.

In conventional fuzzy ANP methodology, decision makers' linguistic evaluations in fuzzy forms are first converted to crisp numbers by using different algorithms and then these crisp evaluations are used in the ANP to perform pairwise comparisons. Contrary to conventional fuzzy ANP methodology in the literature, we use triangular fuzzy numbers in all pairwise comparison matrices through the fuzzy ANP [29]. Hence, criteria weights are calculated as the triangular fuzzy numbers and then these fuzzy criteria weights are used to evaluate the house of quality matrices. This is the most powerful motivation to consider this problem.

The rest of the paper is organized as follows. Sections 2, 3, and 4 describe the basics of the fuzzy ANP, QFD, and fuzzy TOPSIS, respectively. The proposed methodology is given in Section 5. Section 6 presents application of the integrated methodology to the supplier selection problem as a real world case study. The results of the application are discussed and some of the model parameters are evaluated with the sensitivity analysis in Section 7. In Section 8, the conclusions, main findings, and contributions are drawn and future developments are suggested.

\section{Fuzzy ANP}

Fuzzy theory enables decision makers to tackle the ambiguities involved in the process of the linguistic assessment of the data. The theory also allows mathematical operators and programming to apply to the fuzzy domain. It provides numerous methods to represent the qualitative judgment of the decision maker as quantitative data. Triangular fuzzy numbers are used in this paper to assess the preferences of decision makers. The detailed definitions of the fuzzy sets and discussions of the arithmetic operations on triangular fuzzy numbers can be found in Zadeh [30], Dubois and Prade [31], Kaufmann and Gupta [32], Giachetti and Young [33], Wagenknecht et al., [34] and Onut et al. [35].

The ANP is the most comprehensive framework for the analysis of public, governmental, and corporate decisions. 
It allows a decision maker to include all the factors and tangible or intangible criteria that have bearing on making the best decision. The ANP allows both interaction and feedback within clusters of elements (inner dependence) and between clusters (outer dependence). The elements in a cluster may influence other elements in the same cluster and those in other clusters with respect to each of several properties. The main objective is to determine the overall influence of all the elements. In that case, the first of all properties or criteria must be organized and they must be prioritized in the framework of a control hierarchy [36]. Then the comparisons must be performed and synthesized to obtain the priorities of these properties. Additionally, the influence of elements in the feedback system with respect to each of these properties must be derived. Finally, the resulting influences must be weighted by the importance of the properties and added to obtain the overall influence of each element. Before performing the pairwise comparisons, all criteria and clusters compared are linked to each other. Once the pairwise comparisons are completed, local priority vectors are computed. All obtained priority vectors are then normalized to represent the local priority vector. To obtain global priorities, the local priority vectors are entered in the appropriate columns of a matrix of influence among the elements, known as a supermatrix [37]. The supermatrix representation of a hierarchy with three levels is given as follows:

$$
W=\underset{\text { Goal }(G)}{\operatorname{Criteria}(C)} \begin{gathered}
G \\
\text { Alternatives }(A)
\end{gathered}\left(\begin{array}{ccc}
0 & 0 & 0 \\
W_{21} & 0 & 0 \\
0 & W_{32} & I
\end{array}\right)
$$

where $W_{21}$ is a vector that represents the impact of the goal on the criteria, $W_{32}$ is a vector that represents the impact of the criteria on each of the alternatives, and $I$ is the identity matrix. $W$ is referred to as a supermatrix because its entries are matrices. For example, if the criteria are dependent among themselves, then the $(2,2)$ entry of $W$ given by $W_{22}$ would be nonzero. The interdependence is exhibited by the presence of the matrix element $W_{22}$ of the supermatrix $W$ :

$$
W=\left(\begin{array}{ccc}
0 & 0 & 0 \\
W_{21} & W_{22} & 0 \\
0 & W_{32} & I
\end{array}\right) .
$$

A detailed definition of the ANP can be reviewed in Saaty and Vargas [37] and Saaty [38]. In the proposed methodology, the fuzzy ANP has been used to solve the problem of supplier selection. It is very useful in situations, where there is a high degree of interdependence between various attributes of the alternatives. In this approach, pairwise comparison matrices are formed between various attributes of each level with the help of triangular fuzzy numbers. The fuzzy ANP can easily accommodate the interrelationships existing among the functional activities [39]. The concept of supermatrices is employed to obtain the composite weights that overcome the existing interrelationships. The values of parameters are transformed into triangular fuzzy numbers and are used to calculate fuzzy values.

In the pairwise comparison of attributes, a decision maker can use triangular fuzzy numbers to state their preferences.
Saaty's scale of 1-9 is precise and explicit. Even though the discrete scale of 1-9 has the advantages of simplicity and easiness for use, it does not consider the uncertainty associated with the mapping of one's perception or judgment to a number. On the other hand, decision maker's perception about the supplier attributes, like quality, can be vague and ambiguous and hence cannot be expressed in definite numbers. For these reasons a scale of $\widetilde{1}-\widetilde{9}$ can be defined for triangular fuzzy numbers instead of the scale of 1-9. When comparing attribute $i$ with attribute $j, \widetilde{1}, \widetilde{3}, \widetilde{5}, \widetilde{7}$, and $\widetilde{9}$ indicate equal importance among the compared attributes, moderate importance of $i$ over $j$, strong importance of $i$ over $j$, very strong importance of $i$ over $j$, and extreme importance of $i$ over $j$, respectively, where $i=1,2, \ldots, n$, and $j=1,2, \ldots, m$.

To evaluate a decision maker's preferences, pairwise comparison matrices are structured by using triangular fuzzy numbers $(l, m, u)$. The $m \times n$ triangular fuzzy matrix can be given as follows (Ramík [40]):

$$
\widetilde{A}=\left(\begin{array}{cccc}
\left(a_{11}^{l}, a_{11}^{m}, a_{11}^{u}\right) & \left(a_{12}^{l}, a_{12}^{m}, a_{12}^{u}\right) & \ldots & \left(a_{1 n}^{l}, a_{1 n}^{m}, a_{1 n}^{u}\right) \\
\left(a_{21}^{l}, a_{21}^{m}, a_{21}^{u}\right) & \left(a_{22}^{l}, a_{22}^{m}, a_{22}^{u}\right) & \ldots & \left(a_{2 n}^{l}, a_{2 n}^{m}, a_{2 n}^{u}\right) \\
\vdots & \vdots & \vdots & \vdots \\
\left(a_{m 1}^{l}, a_{m 1}^{m}, a_{m 1}^{u}\right) & \left(a_{m 2}^{l}, a_{m 2}^{m}, a_{m 2}^{u}\right) & \ldots & \left(a_{m n}^{l}, a_{m n}^{m}, a_{m n}^{u}\right)
\end{array}\right) .
$$

The element $a_{m n}$ represents the comparison of component $m$ (row element) with component $n$ (column element). If $\widetilde{A}$ is a pairwise comparison matrix, it is assumed that it is reciprocal and the reciprocal value, that is, $1 / \widetilde{a}_{m n}$, is assigned to the element $\tilde{a}_{m n}$ :

$$
\widetilde{A}=\left(\begin{array}{cccc}
(1,1,1) & \left(a_{11}^{l}, a_{11}^{m}, a_{11}^{u}\right) & \ldots & \left(a_{1 n}^{l}, a_{1 n}^{m}, a_{1 n}^{u}\right) \\
\left(\frac{1}{a_{11}^{u}}, \frac{1}{a_{11}^{m}}, \frac{1}{a_{11}^{l}}\right) & (1,1,1) & \cdots & \left(a_{2 n}^{l}, a_{2 n}^{m}, a_{2 n}^{u}\right) \\
\vdots & \vdots & \vdots & \vdots \\
\left(\frac{1}{a_{1 n}^{u}}, \frac{1}{a_{1 n}^{m}}, \frac{1}{a_{1 n}^{l}}\right) & \left(\frac{1}{a_{2 n}^{u}}, \frac{1}{a_{2 n}^{m}}, \frac{1}{a_{2 n}^{l}}\right) & \cdots & (1,1,1)
\end{array}\right) .
$$

$\widetilde{A}$ is also a triangular fuzzy pairwise comparison matrix. There are several methods for getting estimates for fuzzy priorities $\widetilde{w}_{i}$, where $\widetilde{w}_{i}=\left(w_{i}^{l}, w_{i}^{m}, w_{i}^{u}\right), i=1,2, \ldots, n$, from the judgment matrix $\widetilde{A}$ which approximate the fuzzy ratios $\widetilde{a}_{i j}$ so that $\widetilde{a}_{i j} \approx \widetilde{w}_{i} / \widetilde{w}_{j}$. One of these methods, the logarithmic least squares method [41], is reasonable and effective and it is used in this study. Hence, the triangular fuzzy weights for the relative importance of the criteria, the feedback of the criteria, and the alternatives according to the individual criteria can be calculated [40]. In our proposed model, only the triangular fuzzy weights for the relative importance of the criteria and the interdependence priorities of the criteria (see (5)) will be used to support the fuzzy TOPSIS for selecting the best alternative:

$$
W=\left(\begin{array}{cc}
0 & 0 \\
W_{21} & W_{22}
\end{array}\right) .
$$




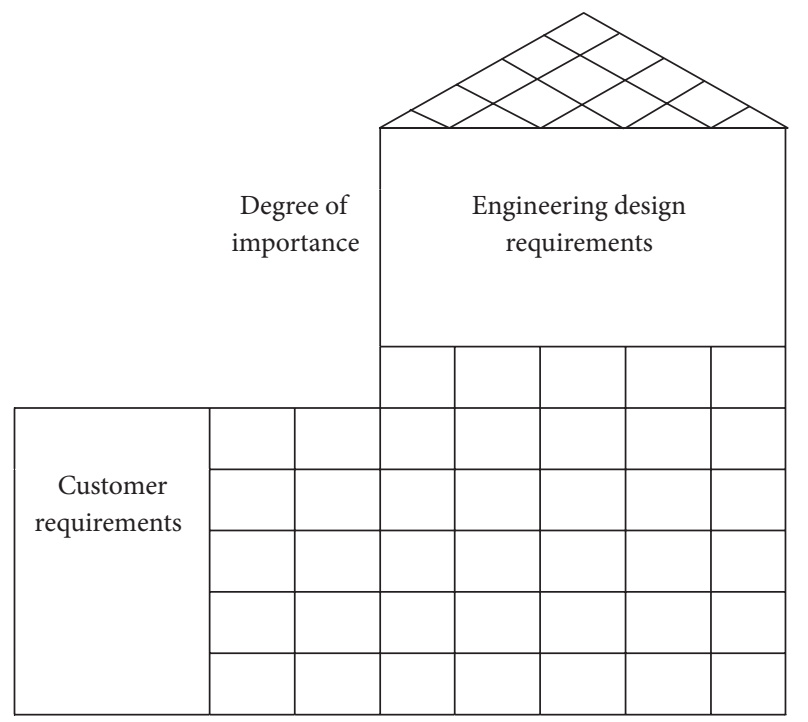

FIGURE 1: QFD relationship matrix.

The logarithmic least squares method for calculating triangular fuzzy weights can be given as follows [40]:

$$
\widetilde{w}_{k}=\left(w_{k}^{l}, w_{k}^{m}, w_{k}^{u}\right) \quad k=1,2,3, \ldots, n,
$$

where

$$
w_{k}^{s}=\frac{\left(\prod_{j=1}^{n} a_{k j}^{s}\right)^{1 / n}}{\sum_{i=1}^{n}\left(\prod_{j=1}^{n} a_{i j}^{m}\right)^{1 / n}}, \quad s \in\{l, m, u\}
$$

\section{QFD}

QFD, developed by Yoji Akao in 1966 and originated in 1972 in Japan, has been a systematic and successful approach to translate customer needs into design characteristics. The main concept of traditional QFD considered four relationship matrices that included product planning, parts planning, process planning, and production planning matrices, respectively $[42,43]$. Each translation uses a matrix, also called house of quality. QFD is a cross-functional planning tool used to help the decision makers. The purpose of the technique is to reduce two types of conflict: first, the conflict that the specification does not comply with the requirements of the customers and, second, the conflict that the final output does not comply with the technical requirements. The relationships between customer requirements and technical requirements in QFD are represented in the matrix form (house of quality) as shown in Figure 1 [44]. The main purpose of QFD in this study is to apply in construction a supplier-oriented selection methodology under the presence of vagueness and to adapt some of the tables and matrices proposed by Akao [45]. A detailed definition of QFD can be found in Akao [45].

\section{Fuzzy TOPSIS}

In the following subsection, some basic important definitions of fuzzy sets from Zimmermann [46], Buckley [47], Zadeh [30], Kaufmann and Gupta [48], Yang and Hung [49], and
Chen et al. [50] are reviewed and summarized. It is often difficult for a decision maker to assign a precise performance rating to an alternative for the criteria under consideration. The merit of using a fuzzy approach is to assign the relative importance of criteria using fuzzy numbers instead of precise numbers. This subsection extends TOPSIS to the fuzzy environment [51].

Definition 1. Let $\tilde{a}=\left(l_{1}, m_{1}, u_{1}\right)$ and $\tilde{b}=\left(l_{2}, m_{2}, u_{2}\right)$ be two triangular fuzzy numbers; then the vertex method is defined to calculate the distance between them as

$$
d(\widetilde{a}, \widetilde{b})=\sqrt{\frac{1}{3}\left[\left(l_{1}-l_{2}\right)^{2}+\left(m_{1}-m_{2}\right)^{2}+\left(u_{1}-u_{2}\right)^{2}\right]} .
$$

The problem can be described by the following sets:

(i) a set of $J$ possible candidates called $A=\left\{A_{1}, A_{2}\right.$, ..., $\left.A_{j}\right\}$

(ii) a set of $n$ criteria, $C=\left\{C_{1}, C_{2}, \ldots, C_{i}\right\}$;

(iii) a set of performance ratings of $A_{j}(j=1,2,3, \ldots, J)$ with respect to criteria $C_{i}(i=1,2,3, \ldots, n)$ called $\widetilde{X}=$ $\left\{\tilde{x}_{i j} i=1,2,3, \ldots, n, j=1,2,3, \ldots, J\right\}$;

(iv) a set of importance weights of each criterion $w_{i}(i=$ $1,2,3, \ldots, n)$.

As stated above, problem matrix format can be expressed as follows:

$$
\widetilde{X}=\left[\begin{array}{cccc}
\tilde{x}_{11} & \tilde{x}_{12} & \cdots & \tilde{x}_{1 n} \\
\tilde{x}_{21} & \tilde{x}_{22} & \cdots & \tilde{x}_{2 n} \\
\vdots & \vdots & \cdots & \vdots \\
\tilde{x}_{J 1} & \tilde{x}_{J 2} & \cdots & \tilde{x}_{J n}
\end{array}\right] .
$$

Definition 2. Considering the different importance values of each criterion, the weighted normalized fuzzy decision matrix is constructed as

$$
\widetilde{V}=\left[\widetilde{v}_{i j}\right]_{n \times J} \quad i=1,2, \ldots, n, j=1,2, \ldots, J,
$$

where $\widetilde{v}_{i j}=\tilde{x}_{i j}(\cdot) w_{i}$.

According to the briefly summarized fuzzy theory above, fuzzy TOPSIS steps can be outlined as follows.

Step 1. Choose the linguistic ratings $\left(\widetilde{x}_{i j} i=1,2,3, \ldots, n, j=\right.$ $1,2,3 \ldots, J)$ for alternatives with respect to criteria. The fuzzy linguistic rating $\left(\widetilde{x}_{i j}\right)$ preserves the property that the ranges of normalized triangular fuzzy numbers belong to $[0,1]$; thus, there is no need for normalization. Let $\widetilde{x}_{i j}=\left(a_{i j}, b_{i j}, c_{i j}\right), \widetilde{x}_{j}=$ $\left(a_{j}^{-}, b_{j}^{-}, c_{j}^{-}\right)$, and $\tilde{x}_{j}^{*}=\left(a_{j}^{*}, b_{j}^{*}, c_{j}^{*}\right)$. We have

$$
\tilde{r}_{i j}=\left\{\begin{array}{l}
\tilde{x}_{i j}(\div) \tilde{x}_{j}^{*}=\left(\frac{a_{i j}}{a_{j}^{*}}, \frac{b_{i j}}{b_{j}^{*}}, \frac{c_{i j}}{c_{j}^{*}}\right), \\
\widetilde{x}_{j}(\div) \tilde{x}_{i j}=\left(\frac{a_{j}^{-}}{a_{i j}}, \frac{b_{j}^{-}}{b_{i j}}, \frac{c_{j}^{-}}{c_{i j}}\right) .
\end{array}\right.
$$


Step 2. Calculate the weighted normalized fuzzy decision matrix. The weighted normalized value $\widetilde{v}_{i j}$ is calculated by (10).

Step 3. Identify positive ideal $\left(A^{*}\right)$ and negative ideal $\left(A^{-}\right)$ solutions. The fuzzy positive ideal solution (FPIS, $A^{*}$ ) and the fuzzy negative ideal solution (FNIS, $A^{-}$) are shown in

$$
\begin{aligned}
& A^{*}=\left\{\widetilde{v}_{1}^{*}, \ldots, \widetilde{v}_{i}^{*}\right\} \\
&=\left\{\left(\max _{j} v_{i j} \mid i \in I^{\prime}\right),\left(\min _{j} v_{i j} \mid i \in I^{\prime \prime}\right)\right\} \\
& i=1,2, \ldots, n, \quad j=1,2, \ldots, J, \\
& A^{-}=\left\{\widetilde{v}_{1}^{-}, \ldots, \widetilde{v}_{i}^{-}\right\} \\
&=\left\{\left(\min _{j} v_{i j} \mid i \in I^{\prime}\right),\left(\max _{j} v_{i j} \mid i \in I^{\prime \prime}\right)\right\} \\
& i=1,2, \ldots, n, \quad j=1,2, \ldots, J,
\end{aligned}
$$

where $I^{\prime}$ is associated with benefit criteria and $I^{\prime \prime}$ is associated with cost criteria.

Step 4. Calculate the distance of each alternative from $A^{*}$ and $A^{-}$using

$$
\begin{array}{ll}
D_{j}^{*}=\sum_{j=1}^{n} d\left(\widetilde{v}_{i j}, \widetilde{v}_{i}^{*}\right) & j=1,2, \ldots, J, \\
D_{j}^{-}=\sum_{j=1}^{n} d\left(\widetilde{v}_{i j}, \widetilde{v}_{i}^{-}\right) & j=1,2, \ldots, J .
\end{array}
$$

Step 5. Calculate similarities to ideal solution:

$$
C C_{j}=\frac{D_{j}^{-}}{D_{j}^{*}+D_{j}^{-}} \quad j=1,2, \ldots, J .
$$

Step 6. Rank preference order. Choose an alternative with maximum $C C_{j}^{*}$ or rank alternatives according to $C C_{j}^{*}$ in descending order.

\section{The Proposed Methodology}

This paper is aimed at calculating the weights of criteria and technical requirements used to evaluate suppliers in the procurement process of a project and to use them to select the appropriate supplier with the proposed methodology. The interaction and feedback within clusters of elements (inner dependence) and between clusters (outer dependence) have to be defined to calculate the weights. For this purpose, the fuzzy ANP method, whose main objective is to determine the overall influence of all the elements, is used. The weights of criteria calculated with that fuzzy ANP method are associated with the house of quality to translate the criteria into the technical requirements in a procurement process. The supermatrix representation of the hierarchy with three levels is given as shown in Figure 2.

The first phase of the proposed methodology starts with defining the criteria to evaluate the suppliers. To set the relationship between the goals and the criteria in the procurement process of a project, procurement experts are included

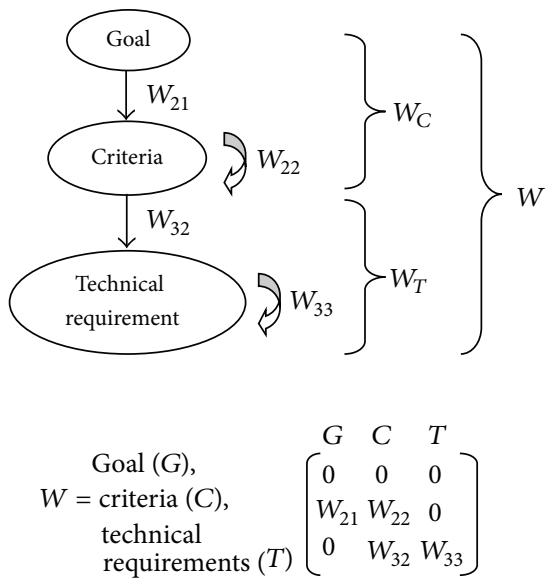

FIgURE 2: The supermatrix and network.

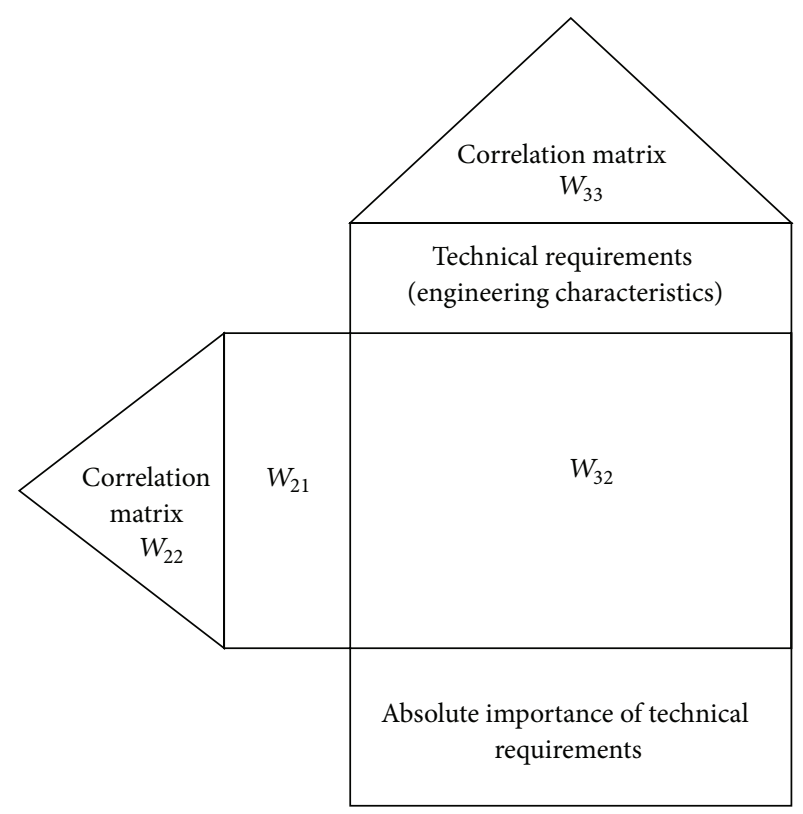

Figure 3: House of quality.

to define the criteria. With the expert evaluation and the use of the fuzzy ANP method, the first matrix $W_{21}$ is calculated. $W_{22}$ is included into the methodology to be sure about the fact that inner dependence of criteria is evaluated for the solution. The fuzzy ANP is again used to calculate $W_{22}$ with the procurement experts' evaluation. $W_{C}$, which is the main matrix used for the weights of criteria, is obtained by the multiplication of $W_{21}$ and $W_{22}$.

In the next steps, the technical requirements are incorporated into the model. Experts from technical departments are asked to define the technical requirements related to the criteria in the procurement process. With the same calculation in $W_{22}$, the inner dependence of the technical requirements is calculated and shown in $W_{33}$.

The relations between the matrices and the house of quality part of the methodology and all of the matrices in the supermatrix are shown in Figure 3. 


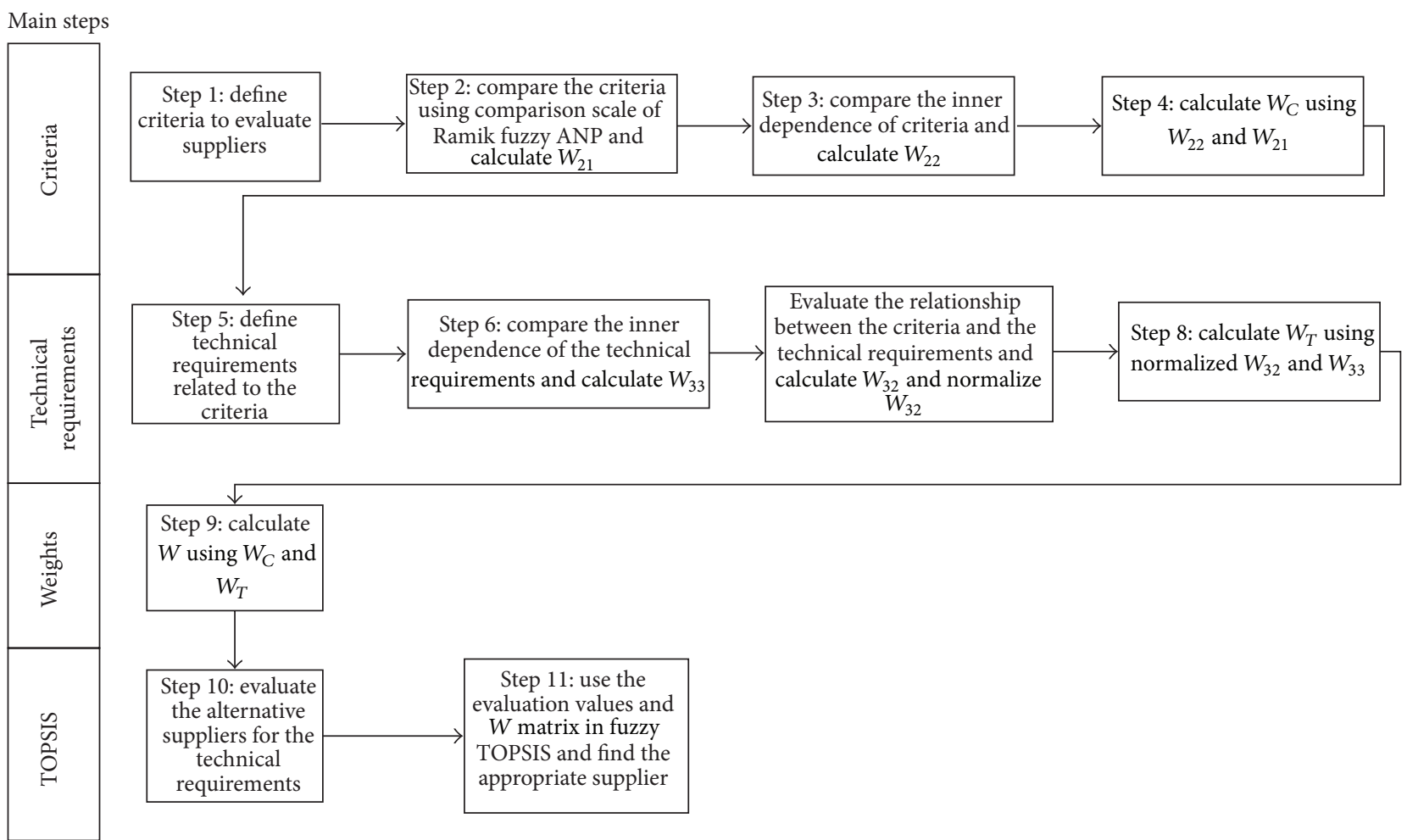

FIgURE 4: The flowchart of the proposed methodology.

TABLE 1: Evaluation scale.

\begin{tabular}{lc}
\hline None & $1,1,1$ \\
Strong negative & $2,3,4$ \\
Negative & $4,5,6$ \\
Positive & $6,7,8$ \\
Strong positive & $8,9,10$ \\
\hline
\end{tabular}

In the house of quality, the criteria are included with $W_{21}$ and $W_{22}$ and the technical requirements are included with $W_{33}$. The technical experts are asked to evaluate the relation between the criteria and the technical requirements to calculate the $W_{32}$ matrix and also $W_{33}$ is calculated with the evaluation of technical experts. The relationships between the criteria and the technical requirements are included with the matrix $W_{32}$. Again the fuzzy ANP method is used to calculate $W_{32}$ matrix to ensure the model uniqueness and then the matrix $W_{32}$ is normalized. As it is defined above with the multiplication of $W_{21}$ and $W_{22}$, the main matrix for the criteria $W_{C}$ is calculated. With the same way, normalized $W_{32}$ and $W_{33}$ are used to calculate the main matrix for the technical requirements $\left(W_{T}\right)$. The relationships between the criteria and the technical requirements are evaluated with the values shown in Table 1.

With the use of $W_{T}$ and $W_{C}$, the last weight matrix $(W)$ is calculated. In the second phase of the proposed methodology fuzzy TOPSIS method is used to find the appropriate supplier with the help of matrix $W$ and the evaluations of the technical experts about the alternative suppliers. The flowchart of the proposed methodology is given in Figure 4. The methodology comprises the following main steps.
TABLE 2: Comparison scale.

\begin{tabular}{lc}
\hline Equal importance & $1,1,1$ \\
Weak importance (of one over the other) & $2,3,4$ \\
Strong importance & $4,5,6$ \\
Demonstrated importance over the other & $6,7,8$ \\
Absolute importance & $8,9,10$ \\
\hline
\end{tabular}

Step 1. The supplier evaluation criteria are defined by the procurement experts.

Step 2. The criteria are compared by the procurement experts again using the comparison scale shown in Table 2 and then $W_{21}$ is calculated. $W_{21}$ is the matrix to define the dependence between the criteria.

Step 3. The inner dependences of the criteria are compared by the procurement experts and $W_{22}$ is calculated. $W_{22}$ is the matrix to define the inner dependence between criteria.

Step 4. $W_{C}$ is calculated with the multiplication of $W_{22}$ and $W_{21} . W_{C}$ is the main matrix to define the weights of the criteria.

Step 5. The technical requirements related to the criteria are defined by the technical experts.

Step 6. The inner dependences of the technical requirements are compared by the technical experts and $W_{33}$ is calculated. $W_{33}$ is the matrix which defines the inner dependence among the technical requirements. 
TABLE 3: Fuzzy TOPSIS evaluation values.

\begin{tabular}{lc}
\hline Very poor & $1,1,1$ \\
Poor & $2,3,4$ \\
Fair & $4,5,6$ \\
Good & $6,7,8$ \\
Very good & $8,9,10$ \\
\hline
\end{tabular}

Step 7. The relationships between the criteria and the technical requirements are evaluated by the technical experts with the scale as shown in Table 1 and then $W_{32}$ is calculated. $W_{32}$ is the matrix to define the relations between the criteria and the technical requirements in the house of quality. After calculation step, $W_{32}$ is normalized so that the elements are unit free. In this step, we use linear scale transformation to obtain the normalized decision matrix.

Step 8. $W_{T}$ is calculated using normalized $W_{32}$ and $W_{33}$. $W_{T}$ is the main matrix to define the weights of the technical requirements.

Step 9. $W$ is calculated using $W_{C}$ and $W_{T} . W$ is the matrix which will be used in the objective function as the weights of the variables (technical requirements).

Step 10. Technical experts evaluate the alternative suppliers for the technical requirements using the evaluation values shown in Table 3.

Step 11. Fuzzy TOPSIS is used to find the appropriate supplier with the help of $W$ and the evaluations of the technical experts.

\section{Application of the Integrated Methodology to the Supplier Selection Problem}

The proposed methodology has a wide application area. The methodology can be used everywhere which has a supplier selection process for projects. As it is mentioned before, criteria to select the supplier are very important and the most important part of this selection is related to the evaluation criteria. The methodology is aimed at calculating the weights of criteria and technical requirements used to evaluate suppliers in the procurement process of a project and to use them to select the appropriate supplier. It will be enough for a decision maker to follow the 11 steps of the methodology.

First of all, evaluation criteria for the selection will be defined by the procurement experts. Procurement experts will compare the importance of the criteria using the scale in Table 2. The evaluations will define $W_{21}$ and $W_{22}$ matrices. In Step $4, W_{C}$ is calculated with the multiplication of $W_{22}$ and $W_{21}$. $W_{C}$ will show the importance weights of the criteria.

Evaluation for the technical requirements will begin in Step 5. Technical experts will define technical requirements and evaluate the importance weights for the technical
TABLE 4: The criteria.

Functional characteristic (FC)

Supplier reliability (SR)

Software perfection level (SPL)

Reference rating (RR)

Application and adaptation support (AAS)

Technical infrastructure (TI)

requirements using the matrices $W_{32}$ and $W_{33}$. The main matrix showing the importance weights for technical requirements $W_{T}$ is calculated using normalized $W_{32}$ and $W_{33}$.

Technical requirements and selection criteria will be combined in matrix $W$ in Step 9. $W$ is the matrix which will be used in the objective function as the weights of the technical requirements.

After the evaluations of criteria and technical requirements, alternative suppliers will be determined and they will be evaluated for the technical requirements using the evaluation values shown in Table 3 .

Finally fuzzy TOPSIS is used to find the appropriate supplier with the help of $W$ and the evaluations of the alternative suppliers. In this study, the proposed methodology is applied to Aktif Bank, which is an investment bank in Turkey. Aktif Bank was established in 1999 under the name Çalıkbank and took its place in the sector as a small investment bank until 2007. In 2007, the bank reshuffled all its senior management and designed a philosophical structure and theoretical background after thousands of hours of studies. In the end they created a new structure called "New Generation Banking." This structure was designed on creating an athletic and entrepreneurial corporation based on existing and near future needs generated by changes in Turkey and around the world. The bank defines its main activities as "direct banking," "city banking," and "regional banking." In order to create and maintain these activities the bank initiated a serious infrastructure study to generate the much-needed workforce, technology, and information capital. In 2008, the bank changed its title to Aktif Bank, believing that this new name better suits its new philosophy.

In this study, procurement process in a software implementation project is considered for the application. In the project, it is planned to buy software and adapt it to the banking processes. The data were obtained by interviewing Aktif Bank's experts. Four experts were incorporated to the study as the technical experts and two as the procurement experts. All the calculations were carried out by using MS Excel. For the first step, "the supplier evaluation criteria are defined by the procurement experts," six criteria to evaluate the suppliers were determined by the procurement experts as follows, and they are also shown in Table 4:

(i) functional characteristic (FC): the criteria to evaluate the characteristics related to the functional capability of the software; 
TABle 5: Pairwise comparison for $W_{21}$.

\begin{tabular}{lcccccccccccccccccc}
\hline & & FC & & \multicolumn{3}{c}{ SR } & \multicolumn{1}{c}{ SPL } & \multicolumn{4}{c}{ RR } & \multicolumn{4}{c}{ AAS } & \multicolumn{3}{c}{ TI } \\
& $L$ & $M$ & $U$ & $L$ & $M$ & $U$ & $L$ & $M$ & $U$ & $L$ & $M$ & $U$ & $L$ & $M$ & $U$ & $L$ & $M$ & $U$ \\
\hline FC & 1 & 1 & 1 & 6 & 7 & 8 & 4 & 5 & 6 & 8 & 9 & 10 & 2 & 3 & 4 & 2 & 3 & 4 \\
SR & 0,125 & 0,143 & 0,167 & 1 & 1 & 1 & 6 & 7 & 8 & 6 & 7 & 8 & 2 & 3 & 4 & 2 & 3 & 4 \\
SPL & 0,167 & 0,2 & 0,25 & 0,125 & 0,143 & 0,167 & 1 & 1 & 1 & 4 & 5 & 6 & 2 & 3 & 4 & 2 & 3 & 4 \\
RR & 0,1 & 0,111 & 0,125 & 0,125 & 0,143 & 0,167 & 0,167 & 0,2 & 0,25 & 1 & 1 & 1 & 2 & 3 & 4 & 2 & 3 & 4 \\
AAS & 0,25 & 0,33 & 0,5 & 0,25 & 0,33 & 0,5 & 0,25 & 0,33 & 0,5 & 0,25 & 0,33 & 0,5 & 1 & 1 & 1 & 2 & 3 & 4 \\
TI & 0,25 & 0,33 & 0,5 & 0,25 & 0,33 & 0,5 & 0,25 & 0,33 & 0,5 & 0,25 & 0,33 & 0,5 & 0,25 & 0,33 & 0,5 & 1 & 1 & 1 \\
\hline
\end{tabular}

TABLE 6: Values of $W_{21}$.

\begin{tabular}{lccc}
\hline & $L$ & $M$ & $U$ \\
\hline FC & 0,36 & 0,45 & 0,53 \\
$R$ & 0,19 & 0,24 & 0,28 \\
SPL & 0,10 & 0,13 & 0,15 \\
RR & 0,05 & 0,07 & 0,08 \\
AAS & 0,05 & 0,07 & 0,10 \\
TI & 0,04 & 0,05 & 0,07 \\
\hline
\end{tabular}

(ii) supplier reliability (SR): the criteria to evaluate the degree of reliability of the supplier;

(iii) software perfection level (SPL): the criteria to make general evaluation about the software as a whole unit different from the functional characteristics;

(iv) reference rating (RR): the criteria to evaluate the rating of the supplier with the information taken from the reference companies;

(v) application and adaptation support (AAS): the criteria to evaluate the suppliers about their capabilities and capacity, for the need of support in application and adaptation process;

(vi) technical infrastructure (TI): the criteria to evaluate the software about the technical properties which are critical for the application and adaptation.

After determining all the selection criteria, the paired comparisons are made by using the triangular fuzzy numbers to tackle the ambiguities involved in the process of the linguistic assessment of the data. The criteria are compared by the procurement experts using the comparison scale (Table 2). The results of these comparisons are shown in Table 5. With the help of Table 5, $W_{21}$ is calculated (Table 6). After this calculation the second step of the methodology is finished.

For the third step, the inner dependences of the criteria are compared by the procurement experts and $W_{22}$ is calculated as shown in Table 7. As it is described before in Step 4, $W_{C}$ which is the main matrix to define the weights of the criteria is calculated with the multiplication of $W_{22}$ and $W_{21}$. $W_{C}$ is shown in Table 8.
After evaluating the selection criteria, the technical experts from the related departments were asked to define the technical requirements for software. For Step 5, the five technical requirements to evaluate the software were determined as follows and they are shown in Table 9:

(i) functional adequacy (FA): the technical requirement to compare the functional capability of the software and the necessities;

(ii) integration with the current system (I): the technical requirement to evaluate the work to integrate the software with the current structure;

(iii) authorization infrastructure (AI): the technical requirement to evaluate the capability of the software about authorization;

(iv) modification easiness (ME): the technical requirement to evaluate the work to modify the software for the desired structure;

(v) enforcement duration (ED): the technical requirement to evaluate the duration of enforcement.

In the next step, the inner dependences of the technical requirements are compared by the technical experts as it is described in Step 6 and $W_{33}$ is calculated as shown in Table 10.

For the use of house of quality, the matrix to define the relation between the criteria and the technical requirements in the house of quality $\left(W_{32}\right)$ is prepared for the calculation by the technical experts' evaluation as it is described in Step 7. After calculation steps of $W_{32}$, it is normalized and then the main matrix to define the weights of the technical requirements $\left(W_{T}\right)$ is calculated by multiplication of normalized $W_{32}$ and $W_{33}$. After this multiplication Step 8 is finished. The related matrices are shown in Tables 11, 12, and 13 .

In Step $9, W_{T}$ and $W_{C}$ are combined with the multiplication process and the matrix $W$, which will be used in the fuzzy TOPSIS method, is obtained. The matrix $W$ is shown in Table 14.

A lot of face-to-face interviews were held with the software procurement experts to develop solid information on the alternative software suppliers. Finally, five suppliers $\left(A_{1}, A_{2}, \ldots, A_{5}\right)$ were involved for evaluation. The experts 
TAble 7: Pairwise comparison for $W_{22}$.

\begin{tabular}{lcccccccccccccccccc}
\hline & & FC & \multicolumn{1}{c}{ SR } & \multicolumn{1}{c}{ SPL } & \multicolumn{4}{c}{ RR } & \multicolumn{4}{c}{ AAS } \\
& $L$ & $M$ & $U$ & $L$ & $M$ & $U$ & $L$ & $M$ & $U$ & $L$ & $M$ & $U$ & $L$ & $M$ & $U$ & $L$ & $M$ & $U$ \\
\hline FC & 0 & 0 & 0 & 0,60 & 0,66 & 0,72 & 0,44 & 0,54 & 0,63 & 0,40 & 0,50 & 0,60 & 0,46 & 0,55 & 0,63 & 0,46 & 0,55 & 0,63 \\
SR & 0,36 & 0,46 & 0,56 & 0 & 0 & 0 & 0,17 & 0,21 & 0,25 & 0,18 & 0,22 & 0,26 & 0,20 & 0,23 & 0,27 & 0,20 & 0,23 & 0,27 \\
SPL & 0,19 & 0,24 & 0,30 & 0,13 & 0,16 & 0,19 & 0 & 0 & 0 & 0,09 & 0,12 & 0,14 & 0,09 & 0,11 & 0,13 & 0,09 & 0,11 & 0,13 \\
RR & 0,10 & 0,13 & 0,16 & 0,07 & 0,08 & 0,10 & 0,08 & 0,10 & 0,12 & 0 & 0 & 0 & 0,04 & 0,05 & 0,06 & 0,04 & 0,05 & 0,06 \\
AAS & 0,08 & 0,10 & 0,14 & 0,05 & 0,06 & 0,08 & 0,07 & 0,09 & 0,13 & 0,08 & 0,10 & 0,13 & 0 & 0 & 0 & 0,04 & 0,05 & 0,08 \\
TI & 0,05 & 0,06 & 0,09 & 0,03 & 0,04 & 0,05 & 0,05 & 0,06 & 0,08 & 0,05 & 0,06 & 0,09 & 0,04 & 0,05 & 0,08 & 0 & 0 & 0 \\
\hline
\end{tabular}

TABLE 8: Values of $W_{C}$.

\begin{tabular}{lccc}
\hline & $L$ & $M$ & $U$ \\
\hline FC & 0,22 & 0,32 & 0,45 \\
$R$ & 0,18 & 0,28 & 0,40 \\
SPL & 0,11 & 0,17 & 0,24 \\
RR & 0,06 & 0,10 & 0,14 \\
AAS & 0,05 & 0,08 & 0,13 \\
TI & 0,03 & 0,05 & 0,09 \\
\hline
\end{tabular}

TABLE 9: Technical requirements.

Functional adequacy (FA)

Integration with the current system (I)

Authorization infrastructure (AI)

Modification easiness (ME)

Enforcement duration (ED)

evaluated the alternative suppliers for the technical requirements in Step 10. The evaluation results are shown in Table 15. After the evaluation of the alternative suppliers, the results are normalized and then $W$ is used to weight the normalized matrix (Table 16).

After calculation steps in fuzzy TOPSIS method, the last step of the methodology, Step 11, is finished and the value for each alternative is found as shown in Table 17. Alternative five is selected as the most appropriate software alternative.

\section{Sensitivity Analysis and Discussions}

In the sensitivity analysis, the idea is to exchange each criterion's weight with another criterion weight as it is used in Önüt et al. [51], so ten different calculations are used. Each alternative is named as $W *$ values for each calculation; for example, $W * 12$ means that the weights of the first and the second criteria have interchanged and $W * 13$ means that the weights of the first and the third criteria have interchanged. Ten calculations are formed and assigned ten different names as $W * 12, W * 13, W * 14, W * 15, W * 23, W * 24, W * 25$, $W * 34, W * 35$, and $W * 45$. In the next step, we use fuzzy TOPSIS method for each alternative. The sensitivity analysis results are shown graphically in Figure 5.

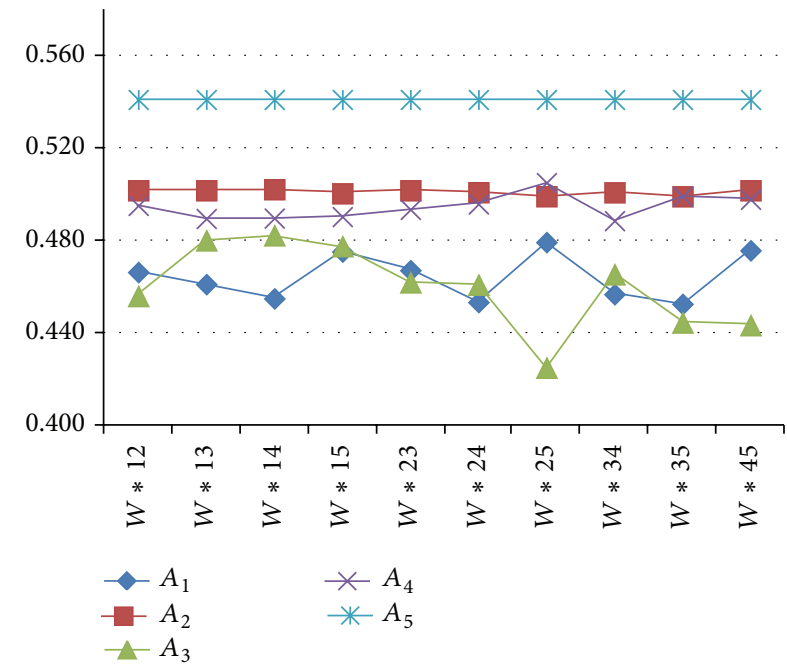

Figure 5: New $W *$ values for the alternatives.

In Figure 5, it can be seen that the ranking in the first, the fifth, the eighth, and the tenth calculation is $A_{5}>A_{2}>A_{4}>$ $A_{1}>A_{3}$, in the second, the third, the fourth, and the sixth calculation is $A_{5}>A_{2}>A_{4}>A_{3}>A_{1}$, and in the seventh and the ninth calculation is $A_{5}>A_{4}>A_{2}>A_{1}>A_{3}$. As can be seen in Figure 5, $A_{5}$ is always the most appropriate alternative, so it proves that $A_{5}$ is the best alternative supplier as we have found in Section 6.

The results for the different calculations show that the most affected alternatives are $A_{3}$ and $A_{1}$. As it can be seen in Figure 5, these alternatives, $A_{3}$ and $A_{1}$, are the last two alternatives in each ranking. As a result it can be said that the model does not affect the most appropriate supplier position in ranking critically.

\section{Conclusions}

In this study, an integrated fuzzy MCDM and QFD methodology has been presented to formulate and solve the supplier selection problem. If the measures are vague, using linguistic preferences can be very useful for uncertain situations. Most of the selection parameters cannot be given precisely and the evaluation data of the alternatives suitability for various subjective criteria and the weights of the criteria are usually expressed in linguistic terms by the decision makers. 
TABle 10: Pairwise comparison for $W_{33}$.

\begin{tabular}{lccccccccccccccc}
\hline & & FA & & & $I$ & & \multicolumn{3}{c}{ AI } & \multicolumn{4}{c}{ ME } & \multicolumn{3}{c}{ ED } \\
& $L$ & $M$ & $U$ & $L$ & $M$ & $U$ & $L$ & $M$ & $U$ & $L$ & $M$ & $U$ & $L$ & $M$ & $U$ \\
\hline FA & 0 & 0 & 0 & 0,49 & 0,58 & 0,67 & 0,42 & 0,51 & 0,60 & 0,40 & 0,50 & 0,58 & 0,41 & 0,51 & 0,60 \\
$I$ & 0,58 & 0,66 & 0,73 & 0 & 0 & 0 & 0,27 & 0,32 & 0,39 & 0,31 & 0,36 & 0,42 & 0,29 & 0,34 & 0,41 \\
AI & 0,15 & 0,18 & 0,21 & 0,19 & 0,23 & 0,27 & 0 & 0 & 0 & 0,09 & 0,10 & 0,11 & 0,07 & 0,09 & 0,10 \\
ME & 0,10 & 0,12 & 0,15 & 0,11 & 0,13 & 0,16 & 0,10 & 0,12 & 0,14 & 0 & 0 & 0 & 0,05 & 0,06 & 0,07 \\
ED & 0,04 & 0,04 & 0,05 & 0,05 & 0,05 & 0,06 & 0,04 & 0,05 & 0,06 & 0,041 & 0,05 & 0,05 & 0,00 & 0,00 & 0,00 \\
\hline
\end{tabular}

TABLE 11: Comparison for $W_{32}$.

\begin{tabular}{lcccccccccccccccccc}
\hline & & FC & & \multicolumn{3}{c}{$R$} & \multicolumn{3}{c}{ SPL } & \multicolumn{3}{c}{ RR } & \multicolumn{3}{c}{ AAS } & \multicolumn{3}{c}{ TI } \\
& $L$ & $M$ & $U$ & $L$ & $M$ & $U$ & $L$ & $M$ & $U$ & $L$ & $M$ & $U$ & $L$ & $M$ & $U$ & $L$ & $M$ & $U$ \\
\hline FA & 8 & 9 & 10 & 6 & 7 & 8 & 8 & 9 & 10 & 6 & 7 & 8 & 6 & 7 & 8 & 6 & 7 & 8 \\
$I$ & 6 & 7 & 8 & 6 & 7 & 8 & 8 & 9 & 10 & 4 & 5 & 6 & 8 & 9 & 10 & 6 & 7 & 8 \\
AI & 8 & 9 & 10 & 6 & 7 & 8 & 8 & 9 & 10 & 4 & 5 & 6 & 4 & 5 & 6 & 6 & 7 & 8 \\
ME & 6 & 7 & 8 & 4 & 5 & 6 & 6 & 7 & 8 & 4 & 5 & 6 & 8 & 9 & 10 & 6 & 7 & 8 \\
ED & 6 & 7 & 8 & 4 & 5 & 6 & 6 & 7 & 8 & 4 & 5 & 6 & 8 & 9 & 10 & 6 & 7 & 8 \\
\hline
\end{tabular}

TABLE 12: Normalized $W_{32}$.

\begin{tabular}{lcccccccccccccccccc}
\hline & & FC & & & $R$ & \multicolumn{1}{c}{ SPL } & \multicolumn{4}{c}{ RR } & \multicolumn{4}{c}{ AAS } & \multicolumn{3}{c}{ TI } \\
& $L$ & $M$ & $U$ & $L$ & $M$ & $U$ & $L$ & $M$ & $U$ & $L$ & $M$ & $U$ & $L$ & $M$ & $U$ & $L$ & $M$ & $U$ \\
\hline FA & 1 & 1 & 1 & 0,75 & 0,78 & 0,8 & 1 & 1 & 1 & 0,75 & 0,78 & 0,8 & 0,75 & 0,78 & 0,8 & 0,75 & 0,78 & 0,8 \\
$I$ & 0,75 & 0,78 & 0,8 & 0,75 & 0,78 & 0,8 & 1 & 1 & 1 & 0,5 & 0,56 & 0,6 & 1 & 1 & 1 & 0,75 & 0,78 & 0,8 \\
AI & 1 & 1 & 1 & 0,75 & 0,78 & 0,8 & 1 & 1 & 1 & 0,5 & 0,56 & 0,6 & 0,5 & 0,56 & 0,6 & 0,75 & 0,78 & 0,8 \\
ME & 0,75 & 0,78 & 0,8 & 0,5 & 0,56 & 0,6 & 0,75 & 0,78 & 0,8 & 0,5 & 0,56 & 0,6 & 1 & 1 & 1 & 0,75 & 0,78 & 0,8 \\
ED & 0,75 & 0,78 & 0,8 & 0,5 & 0,56 & 0,6 & 0,75 & 0,78 & 0,8 & 0,5 & 0,56 & 0,6 & 1 & 1 & 1 & 0,75 & 0,78 & 0,8 \\
\hline
\end{tabular}

TABLE 13: Values of $W_{T}$.

\begin{tabular}{lcccccccccccccccccc}
\hline & & FC & & \multicolumn{1}{c}{$R$} & \multicolumn{1}{c}{ SPL } & \multicolumn{4}{c}{ RR } & \multicolumn{4}{c}{ AAS } & \multicolumn{3}{c}{ TI } \\
& $L$ & $M$ & $U$ & $L$ & $M$ & $U$ & $L$ & $M$ & $U$ & $L$ & $M$ & $U$ & $L$ & $M$ & $U$ & $L$ & $M$ & $U$ \\
\hline FA & 1,40 & 1,75 & 2,09 & 1,09 & 1,41 & 1,73 & 1,52 & 1,88 & 2,22 & 0,86 & 1,17 & 1,48 & 1,52 & 1,88 & 2,22 & 1,29 & 1,64 & 1,97 \\
$I$ & 1,17 & 1,38 & 1,64 & 1,09 & 1,30 & 1,54 & 1,17 & 1,38 & 1,64 & 1,02 & 1,23 & 1,46 & 1,33 & 1,54 & 1,80 & 1,24 & 1,46 & 1,71 \\
AI & 0,37 & 0,46 & 0,56 & 0,37 & 0,46 & 0,55 & 0,42 & 0,51 & 0,61 & 0,32 & 0,41 & 0,50 & 0,50 & 0,59 & 0,69 & 0,41 & 0,50 & 0,60 \\
ME & 0,30 & 0,36 & 0,44 & 0,28 & 0,35 & 0,43 & 0,33 & 0,39 & 0,47 & 0,23 & 0,29 & 0,37 & 0,31 & 0,38 & 0,46 & 0,30 & 0,36 & 0,44 \\
ED & 0,14 & 0,16 & 0,19 & 0,12 & 0,15 & 0,18 & 0,15 & 0,17 & 0,20 & 0,10 & 0,12 & 0,15 & 0,15 & 0,17 & 0,20 & 0,13 & 0,16 & 0,19 \\
\hline
\end{tabular}

TABLE 14: Values of $W$.

\begin{tabular}{lccc}
\hline & $L$ & $M$ & $U$ \\
\hline FA & 0,80 & 1,54 & 2,67 \\
$I$ & 0,71 & 1,28 & 2,19 \\
AI & 0,24 & 0,45 & 0,78 \\
ME & 0,18 & 0,34 & 0,60 \\
ED & 0,08 & 0,15 & 0,25 \\
\hline
\end{tabular}

This makes fuzzy logic a more natural approach to this kind of problems. For this reason fuzzy ANP and QFD are used to define the weight of the criteria for evaluation and fuzzy TOPSIS is used to select the appropriate supplier with the defined weights and evaluations. Inner dependencies for the criteria and the technical requirements are considered with the use of fuzzy ANP. The application for the proposed methodology is made by an investment bank as a real world case study in Turkey. The results guide companies to choose the best supplier among the candidates.

Although there are some papers which applied these techniques in fuzzy manner separately in the literature, there is no evidence that a combining approach has been utilized. This methodology is used for the first time as a decision aiding process for a supplier selection problem in banking sector. Moreover the proposed methodology is very flexible and easy to utilize for group decision-making systems. We find that the proposed method is practical for ranking 
TABLE 15: Decision matrix for alternatives in fuzzy TOPSIS.

\begin{tabular}{llcccccccccccccc}
\hline & & $A_{1}$ & & & $A_{2}$ & & & $A_{3}$ & & $A_{4}$ & \multicolumn{3}{c}{$A_{5}$} \\
& $L$ & $M$ & $U$ & $L$ & $M$ & $U$ & $L$ & $M$ & $U$ & $L$ & $M$ & $U$ & $L$ & $M$ & $U$ \\
\hline FA & 4 & 5 & 6 & 6 & 7 & 8 & 2 & 3 & 4 & 6 & 7 & 8 & 8 & 9 & 10 \\
$I$ & 4 & 5 & 6 & 6 & 7 & 8 & 6 & 7 & 8 & 4 & 5 & 6 & 8 & 9 & 10 \\
$\mathrm{AI}$ & 8 & 9 & 10 & 6 & 7 & 8 & 6 & 7 & 8 & 6 & 7 & 8 & 8 & 9 & 10 \\
$\mathrm{ME}$ & 2 & 3 & 4 & 4 & 5 & 6 & 6 & 7 & 8 & 4 & 5 & 6 & 6 & 7 \\
$\mathrm{ED}$ & 4 & 5 & 6 & 4 & 5 & 6 & 2 & 3 & 4 & 6 & 7 & 8 & 6 & 7 \\
\hline
\end{tabular}

TABLE 16: The weighted normalized decision matrix.

\begin{tabular}{lccccccccccccccc}
\hline & & $A_{1}$ & & \multicolumn{3}{c}{$A_{2}$} & \multicolumn{3}{c}{$A_{3}$} & \multicolumn{3}{c}{$A_{4}$} & \multicolumn{4}{c}{$A_{5}$} \\
& $L$ & $M$ & $U$ & $L$ & $M$ & $U$ & $L$ & $M$ & $U$ & $L$ & $M$ & $U$ & $L$ & $M$ & $U$ \\
\hline FA & 0,40 & 0,86 & 1,60 & 0,60 & 1,20 & 2,13 & 0,20 & 0,51 & 1,07 & 0,60 & 1,20 & 2,13 & 0,80 & 1,54 & 2,67 \\
$I$ & 0,35 & 0,71 & 1,31 & 0,53 & 1,00 & 1,75 & 0,53 & 1,00 & 1,75 & 0,35 & 0,71 & 1,31 & 0,71 & 1,28 & 2,19 \\
AI & 0,24 & 0,45 & 0,78 & 0,18 & 0,35 & 0,62 & 0,18 & 0,35 & 0,62 & 0,18 & 0,35 & 0,62 & 0,24 & 0,45 & 0,78 \\
ME & 0,06 & 0,14 & 0,30 & 0,12 & 0,24 & 0,45 & 0,18 & 0,34 & 0,60 & 0,12 & 0,24 & 0,45 & 0,18 & 0,34 & 0,60 \\
ED & 0,05 & 0,10 & 0,19 & 0,05 & 0,10 & 0,19 & 0,03 & 0,06 & 0,13 & 0,08 & 0,15 & 0,25 & 0,08 & 0,15 & 0,25 \\
\hline
\end{tabular}

TABLE 17: Supplier selection results.

\begin{tabular}{llll}
\hline & $d_{1}{ }^{+}$ & $d_{1}{ }^{-}$ & CCi \\
\hline$A_{1}$ & 3,22 & 2,82 & 0,47 \\
$A_{2}$ & 3,49 & 3,51 & 0,50 \\
$A_{3}$ & 3,28 & 2,81 & 0,46 \\
$A_{4}$ & 3,38 & 3,24 & 0,49 \\
$\mathbf{A}_{\mathbf{5}}$ & $\mathbf{3 , 7 9}$ & $\mathbf{4 , 4 8}$ & $\mathbf{0 , 5 4}$ \\
\hline
\end{tabular}

alternatives with respect to multiple conflicting criteria for the large scale problems. For further research, different fuzzy ANP approaches and fuzzy multicriteria decision-making methods may be used to compare with the results obtained in this paper. Also, the proposed methodology may be used in different selection problems.

\section{Conflict of Interests}

The authors declare that there is no conflict of interests regarding the publication of this paper.

\section{Acknowledgment}

The authors express their sincere thanks and appreciations to the Aktif Investment Bank for their invaluable contributions on this research.

\section{References}

[1] S. Talluri and R. Narasimhan, "A methodology for strategic sourcing," European Journal of Operational Research, vol. 154, no. 1, pp. 236-250, 2004.

[2] A. Bhattacharya, J. Geraghty, and P. Young, "Supplier selection paradigm: an integrated hierarchical QFD methodology under multiple-criteria environment," Applied Soft Computing Journal, vol. 10, no. 4, pp. 1013-1027, 2010.
[3] O. C. T. Onesime, X. Xiaofei, and Z. Dechen, "A decision support system for supplier selection process," International Journal of Information Technology \& Decision Making, vol. 3, no. 3, pp. 453-470, 2004.

[4] H.-T. Liu and C.-H. Wang, "An advanced quality function deployment model using fuzzy analytic network process," Applied Mathematical Modelling, vol. 34, no. 11, pp. 3333-3351, 2010.

[5] R. Yu and G.-H. Tzeng, "A soft computing method for multicriteria decision making with dependence and feedback," Applied Mathematics and Computation, vol. 180, no. 1, pp. 63-75, 2006.

[6] U. R. Tuzkaya and S. Önüt, "A fuzzy analytic network process based approach to transportation-mode selection between Turkey and Germany: a case study," Information Sciences, vol. 178, no. 15, pp. 3132-3145, 2008.

[7] G. Büyüközkan, T. Ertay, C. Kahraman, and D. Ruan, "Determining the importance weights for the design requirements in the house of quality using the fuzzy analytic network approach," International Journal of Intelligent Systems, vol. 19, no. 5, pp. 443-461, 2004.

[8] T. Ertay, G. Büyüközkan, C. Kahraman, and D. Ruan, "Quality function deployment implementation based on analytic network process with linguistic data: an application in automotive industry," Journal of Intelligent and Fuzzy Systems, vol. 16, no. 3, pp. 221-232, 2005.

[9] C. Kahraman, T. Ertay, and G. Büyüközkan, “A fuzzy optimization model for QFD planning process using analytic network approach," European Journal of Operational Research, vol. 171, no. 2, pp. 390-411, 2006.

[10] A. H. I. Lee, H.-Y. Kang, C.-Y. Yang, and C.-Y. Lin, "An evaluation framework for product planning using FANP, QFD and multi-choice goal programming," International Journal of Production Research, vol. 48, no. 13, pp. 3977-3997, 2010.

[11] X. Geng, X. Chu, D. Xue, and Z. Zhang, "An integrated approach for rating engineering characteristics' final importance in product-service system development," Computers and Industrial Engineering, vol. 59, no. 4, pp. 585-594, 2010. 
[12] Y. Lin, H.-P. Cheng, M.-L. Tseng, and J. C. C. Tsai, "Using QFD and ANP to analyze the environmental production requirements in linguistic preferences," Expert Systems with Applications, vol. 37, no. 3, pp. 2186-2196, 2010.

[13] Z. Güngör, E. K. Delice, and S. E. Kesen, "New product design using FDMS and FANP under fuzzy environment," Applied Soft Computing Journal, vol. 11, no. 4, pp. 3347-3356, 2011.

[14] K. Li, Y. Zhang, and W. Liu, "Weight analysis based on ANP and QFD in software quality evaluation," Applied Mathematics \& Information Sciences, vol. 8, no. 2, pp. 793-798, 2014.

[15] T. Ertay, D. E. Akyol, and C. Araz, "An integrated fuzzy approach for determining engineering characteristics in concrete industry," Applied Artificial Intelligence, vol. 25, no. 4, pp. 305-327, 2011.

[16] A. H. I. Lee and C.-Y. Lin, "An integrated fuzzy QFD framework for new product development," Flexible Services and Manufacturing Journal, vol. 23, no. 1, pp. 26-47, 2011.

[17] H.-T. Liu, "An integrated fuzzy decision approach for product design and evaluation," Journal of Intelligent \& Fuzzy Systems, vol. 25, no. 3, pp. 709-721, 2013.

[18] C. L. Hwang and K. Yoon, Multiple Attribute Decision Making Methods and Applications: A State of the Art Survey, Springer, New York, NY, USA, 1981.

[19] E. E. Karsak, "Distance-based fuzzy MCDM approach for evaluating flexible manufacturing system alternatives," International Journal of Production Research, vol. 40, no. 13, pp. 3167-3181, 2002.

[20] S. Onut, S. S. Kara, and S. Mert, "Selecting the suitable material handling equipment in the presence of vagueness," International Journal of Advanced Manufacturing Technology, vol. 44, no. 7-8, pp. 818-828, 2009.

[21] M. Bevilacqua, F. E. Ciarapica, and G. Giacchetta, "A fuzzy-QFD approach to supplier selection," Journal of Purchasing \& Supply Management, vol. 12, no. 1, pp. 14-27, 2006.

[22] S. H. Amin and J. Razmi, "An integrated fuzzy model for supplier management: a case study of ISP selection and evaluation," Expert Systems with Applications, vol. 36, no. 4, pp. 8639-8648, 2009.

[23] Y.-K. Juan, Y.-H. Perng, D. Castro-Lacouture, and K.-S. Lu, "Housing refurbishment contractors selection based on a hybrid fuzzy-QFD approach," Automation in Construction, vol. 18, no. 2, pp. 139-144, 2009.

[24] S. Önüt, S. S. Kara, and E. Işik, "Long term supplier selection using a combined fuzzy MCDM approach: a case study for a telecommunication company," Expert Systems with Applications, vol. 36, no. 2, pp. 3887-3895, 2009.

[25] G. Büyüközkan and G. Çifçi, "A novel hybrid MCDM approach based on fuzzy DEMATEL, fuzzy ANP and fuzzy TOPSIS to evaluate green suppliers," Expert Systems with Applications, vol. 39, no. 3, pp. 3000-3011, 2012.

[26] J. Soroor, M. J. Tarokh, F. Khoshalhan, and S. Sajjadi, "Intelligent evaluation of supplier bids using a hybrid technique in distributed supply chains," Journal of Manufacturing Systems, vol. 31, no. 2, pp. 240-252, 2012.

[27] J. Dai and J. Blackhurst, "four-phase AHP-QFD approach for supplier assessment: a sustainability perspective," International Journal of Production Research, vol. 50, no. 19, pp. 5474-5490, 2012.

[28] C.-M. Wu, C.-L. Hsieh, and K.-L. Chang, "A hybrid multiple criteria decision making model for supplier selection," Mathematical Problems in Engineering, vol. 2013, Article ID 324283, 8 pages, 2003.
[29] J. Ramík and R. Perzina, "A method for solving fuzzy multicriteria decision problems with dependent criteria," Fuzzy Optimization and Decision Making, vol. 9, no. 2, pp. 123-141, 2010.

[30] L. A. Zadeh, "Fuzzy sets," Information and Control, vol. 8, no. 3, pp. 338-353, 1965.

[31] D. Dubois and H. Prade, "Operation on fuzzy numbers," The International Journal of Systems Sciences, vol. 9, no. 6, pp. 613626, 1978.

[32] A. Kaufmann and M. M. Gupta, Fuzzy Mathematical Models in Engineering and Management Science, North-Holland, Amsterdam, The Netherlands, 1988.

[33] R. E. Giachetti and R. E. Young, "A parametric representation of fuzzy numbers and their arithmetic operators," Fuzzy Sets and Systems, vol. 91, pp. 185-202, 1997.

[34] M. Wagenknecht, R. Hampel, and V. Schneider, "Computational aspects of fuzzy arithmetics based on Archimedean t-norms," Fuzzy Sets and Systems, vol. 123, no. 1, pp. 49-62, 2001.

[35] S. Onut, U. R. Tuzkaya, and E. Torun, "Selecting container port via a fuzzy ANP-based approach: a case study in the Marmara Region, Turkey," Transport Policy, vol. 18, no. 1, pp. 182-193, 2011.

[36] R. W. Saaty, "Decision making in complex environment: the analytic hierarchy process (AHP) for decision making and the analytic network process (ANP) for decision making with dependence and feedback," 2003, http://www.Superdecisions . $\mathrm{com} /$.

[37] T. L. Saaty and L. G. Vargas, "Diagnosis with dependent symptoms: Bayes theorem and the analytic hierarchy process," Operations Research, vol. 46, no. 4, pp. 491-502, 1998.

[38] T. L. Saaty, Fundamentals of the Analytic Network Process, ISAHP, Kobe, Japan, 1999.

[39] R. P. Mohanty, R. Agarwal, A. K. Choudhury, and M. K. Tiwari, "A fuzzy ANP-based approach to R\&D project selection: a case study," International Journal of Production Research, vol. 43, no. 24, pp. 5199-5216, 2005.

[40] J. Ramík, "A decision system using anp and fuzzy inputs," International Journal of Innovative Computing, Information and Control, vol. 3, no. 4, pp. 825-837, 2007.

[41] S. J. Chen, C. L. Hwang, and F. P. Hwang, Fuzzy Multiple Attribute Decision Making, vol. 375 of Lecture Notes in Economics and Math. Syst, 1992.

[42] Y. Akao, "QFD: past, present, and future," in Proceedings of the International Symposium on QFD, Linköping, Germany, 1997.

[43] E. E. Karsak, S. Sozer, and S. E. Alptekin, "Product planning in quality function deployment using a combined analytic network process and goal programming approach," Computers and Industrial Engineering, vol. 44, no. 1, pp. 171-190, 2003.

[44] H. Malekly, S. Meysam Mousavi, and H. Hashemi, "A fuzzy integrated methodology for evaluating conceptual bridge design," Expert Systems with Applications, vol. 37, no. 7, pp. 4910-4920, 2010.

[45] Y. Akao, "An introduction to quality function deployment," in Quality Function Deployment (QFD): Integrating Customer Requirements Into Product Design, Y. Akao, Ed., Productivity Press, Cambridge, Mass, USA, 1990.

[46] H. J. Zimmermann, Fuzzy Set Theory and Its Applications, Kluwer Academic Publishers, London, UK, 2nd edition, 1991.

[47] J. J. Buckley, "Fuzzy hierarchical analysis," Fuzzy Sets and Systems, vol. 17, no. 3, pp. 233-247, 1985.

[48] A. Kaufmann and M. M. Gupta, Introduction to Fuzzy Arithmetic: Theory and Applications, Van Nostrand Reinhold, New York, NY, USA, 1991. 
[49] T. Yang and C.-C. Hung, "Multiple-attribute decision making methods for plant layout design problem," Robotics and Computer-Integrated Manufacturing, vol. 23, no. 1, pp. 126-137, 2007.

[50] C.-T. Chen, C.-T. Lin, and S.-F. Huang, "A fuzzy approach for supplier evaluation and selection in supply chain management," International Journal of Production Economics, vol. 102, no. 2, pp. 289-301, 2006.

[51] S. Önüt, T. Efendigil, and S. S. Kara, "A combined fuzzy MCDM approach for selecting shopping center site: an example from Istanbul, Turkey," Expert Systems with Applications, vol. 37, no. 3, pp. 1973-1980, 2010. 


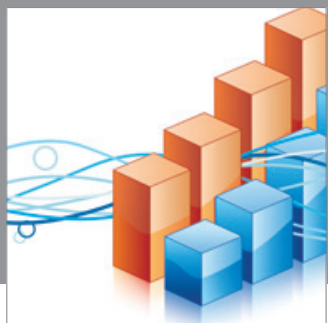

Advances in

Operations Research

mansans

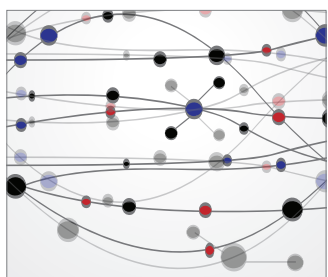

The Scientific World Journal
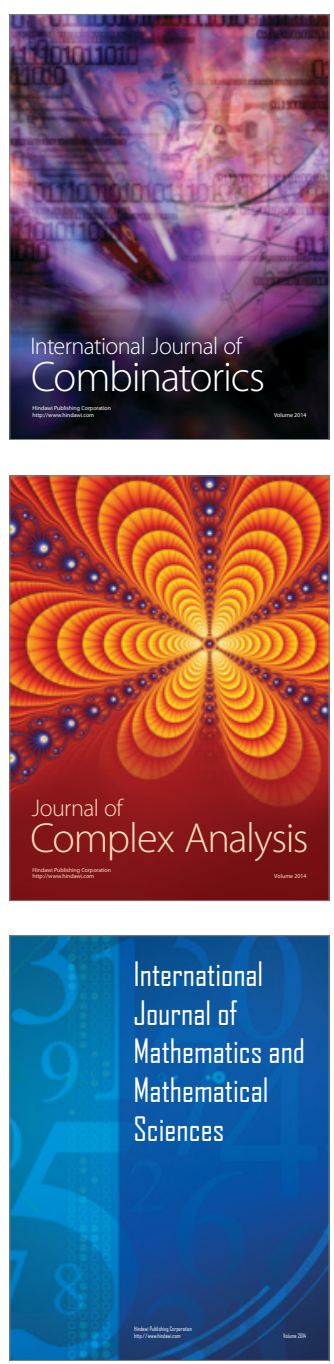
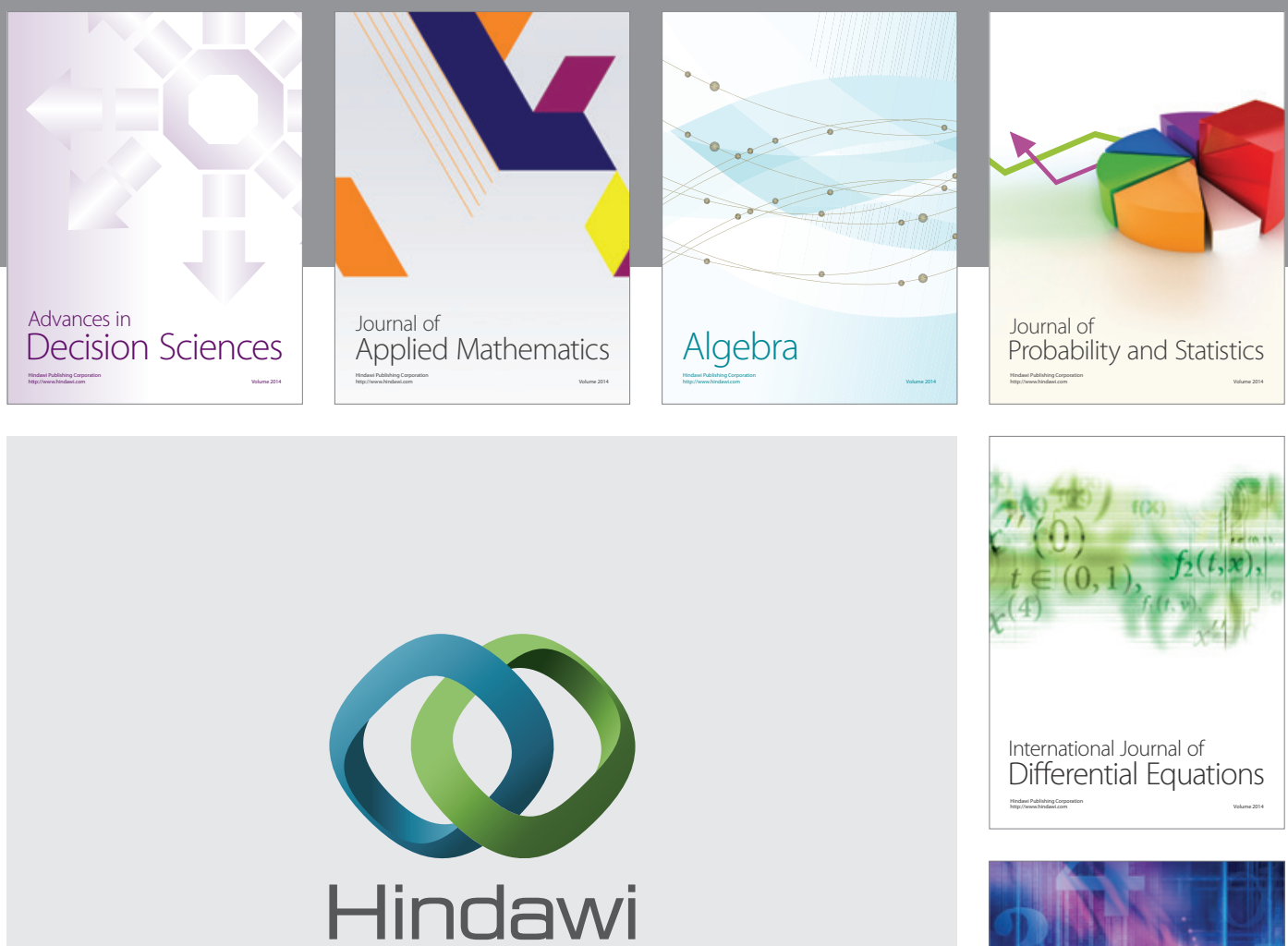

Submit your manuscripts at http://www.hindawi.com
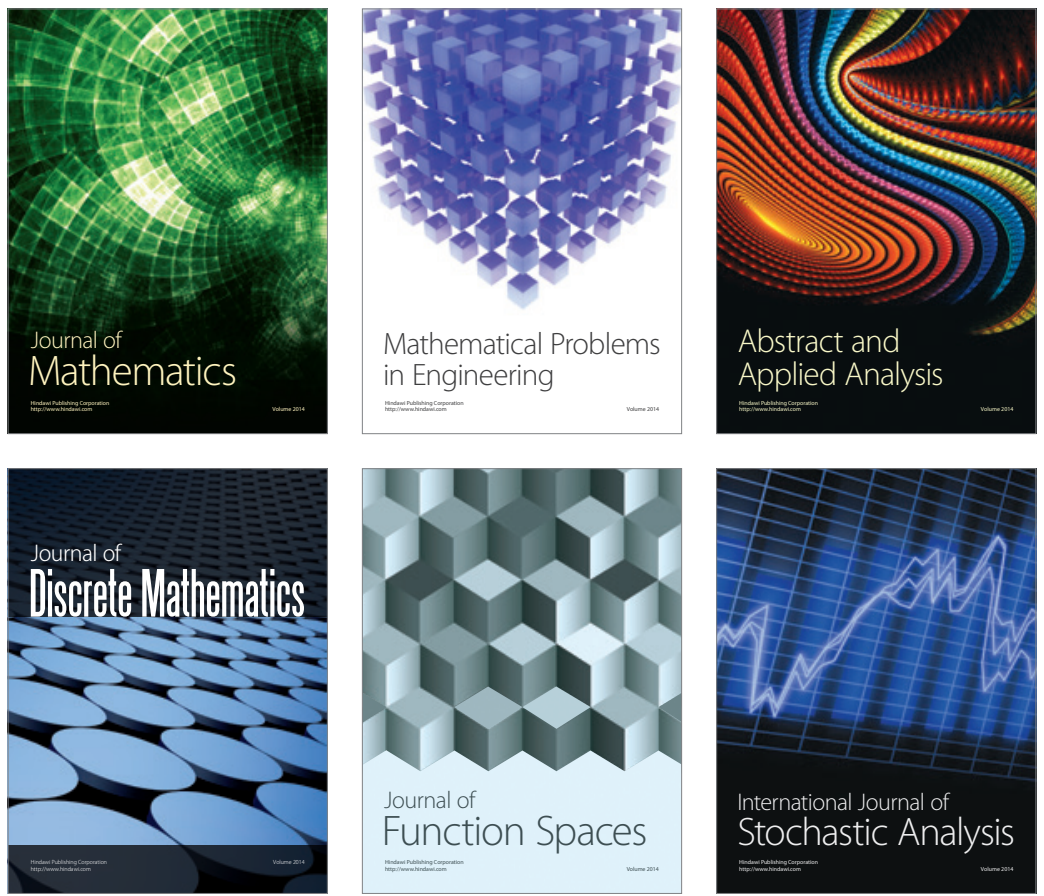

Journal of

Function Spaces

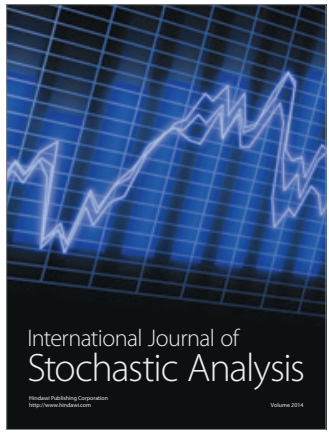

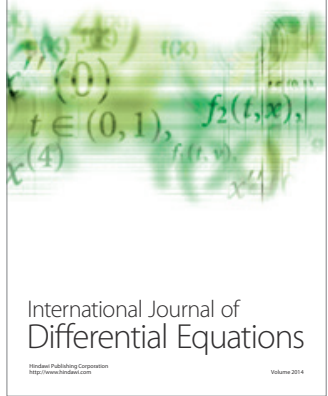
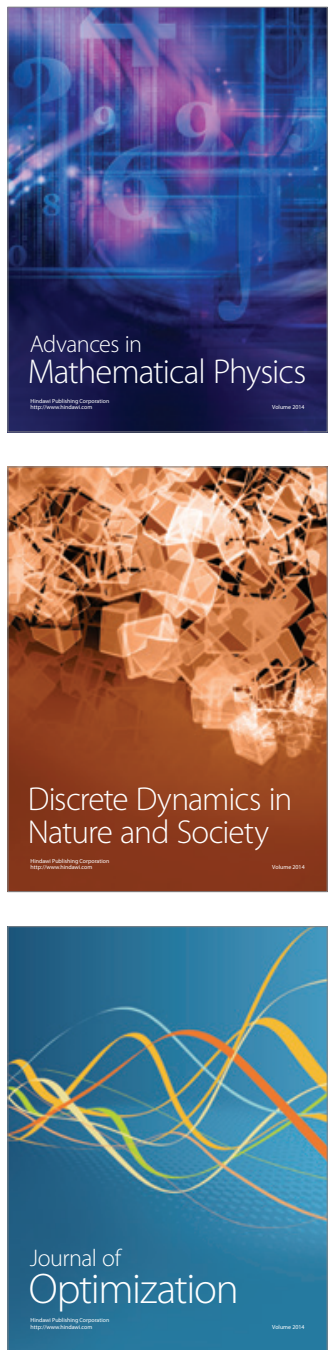